\title{
СЕМАНТИКО-СИНТАКСИЧЕСКИЕ СТРУКТУРЫ КАК КОГНИТИВНЫЙ ФАКТОР РЕАЛЬНОГО ПРОЦЕССА РЕЧЕПОРОЖДЕНИЯ
}

\section{SEMANTIC-SYNTACTIC STRUCTURES AS A COGNITIVE FACTOR OF THE REAL PROCESS OF RECEPTION}

T. Abdukadyrova

M. Arsakhanova

Summary: The purpose of the article is to understand and scientifically substantiate the concept of « deep semantic structures «and try to identify the objective basis of» deep semantic structures « in unity with the idea of transition from the initial stage of speech generation to its final stage.

The author confirms that the content of «deep semantic structures» is revealed by linguistic research as invariants of synonymous transformations. The linguistic content of the utterance can be isolated as a component of the total semantic content of the utterance, which is directly caused by the language information.

Thus, the author sees this as a bridge of generality that leads from the problem of integral semantic contents of individual minimal utterances to the problem of a "large" coherent text.

Keywords: deep semantic structures, surface procedures, linguistic competence, speech-thinking process, speech generation, hypostasis, idioethnic character, internal programming, cognitive, internal speech, correlates, coding.
$\mathrm{B}$ статье рассматривается соотношение, получившее широкое распространенное терминологическое выражение как соотношение «глубинных структур» и «поверхностных процедур». У Н. Хомского, который ввел эти понятия в научный оборот, они не имеют однозначного смысла. Вместе с тем концепция Н. Хомского отражает настоятельную необходимость различать информацию, представленную набором языковых элементов - в их взаимосвязях языковых и взаимоограничениях - в предложении, т.е. информацию «поверхностного» плана, которую можно назвать непосредственно языковой информацией, непосредственно языковым семантическим содержанием, и то, что вслед за Н. Хомским принято называть «глубинной структурой»[12,с.97], часто уточняя термин «структура» атрибутами «синтаксическая» или «семантическая», и что так или иначе стоит «за» семантическим содержанием, выражаемым конкретно-языковым составом и взаимосвязями знаков в высказывании-предложении.

\author{
Абдукадырова Тумиша Таштиевна, \\ к.п.н., дочент, Чеченский государственный университет \\ tumischa-uni@mail.ru \\ Арсаханова Малютхан Абдул-Хаджиевна \\ к.ф.н., дочент, Чеченский государственный университет \\ arsahanova@mail.ru
}

Аннотация: Целью статьи является осмысление и научное обоснование понятия «глубинные семантические структуры» и попытка выявить объективное основание «глубинных семантических структур» в единстве с идеей перехода от исходного этапа порождения речи к его конечному этапу.

Автор подтверждает то, что содержание «глубинных семантических структур» выявляется лингвистическими исследованиями как инварианты синонимических преобразований. Языковое же содержание высказывания может вычленяться как компонент совокупного семантического содержания высказывания, обусловленных непосредственно языковой информацией. Таким образом, автор видит в этом тот мостик общности, который ведет от проблематики целостных семантических содержаний отдельных минимальных высказываний к проблематике «большого» связного текста.

Ключевые слова: глубинные семантические структуры, поверхностные процедуры, лингвистическая компетенция, речемыслительный процесс, речепорождение, гипостазирование, идиоэтнический характер, внутреннее программирование, когнитивный, внутренняя речь, коррелаты, кодирование.

«Глубинные структуры», как они осмыслены у Н. Хомского и его последователей, подвергнуты, с нашей точки зрения, наиболее основательной принципиальной критике С.Д. Кацнельсоном [12, с. 102]. Эту критику можно концентрированно выразить в положении о том, что у «глубинных структур» Н. Хомского нет онтологического статуса относительно реального процесса речепорождения и они фактически выводятся в порядке осуществления моделирующих процедур из «поверхностных структур» $[9$, с.45].

Многие авторы отмечали необоснованность претензий на то, что «глубинные структуры» являются компонентом действительной «лингвистической компетенции», как в американской лингвистике принято называть языковую способность.

Тем не менее хотя понятие «глубинных» синтаксических и/или семантических структур критиковалось с разных позиций многими авторами, вопрос об отноше- 
нии «глубинных» структур к некоторым реальностям речемыслительного процесса остается актуальным. «Глубинное» в семантике предложений функционирует в теоретических построениях многих лингвистов, выполняя в этих построениях ответственные роли. Показательно, что С.Д. Кацнельсон, отвергая трактовку «глубинных структур» у Н. Хомского, признает вместе с тем реальность некоего семантического уровня, на который указывает атрибут «глубинной», и, например, в книге «Типология языка и речевое мышление» употребляет в позитивном смысле уже свой термин «глубинная семантико-синтаксическая структура». В этой тенденции проявляется объективная значимость и важная теоретическая функция представления о том, что непосредственно воспринимаемая языковая текстовая данность формируется движением от яруса, на который мы пока в самой общей форме укажем, как на какой-то начальный этап в развертывании отражательного процесса, где появляется исходный материал, перерабатываемый затем собственно когнитивный образ [9, с.89].

В психологии речи и психолингвистике уже имеется концептуальная схема речепорождающего процесса, охватывающую потребность, мотивацию, цель, этап внутреннего программирования, этап реализации многоаспектной программы высказывания сличение реализации и программы на разных уровнях осознанности контроля и в случае необходимости этап коррекции. Из перечисленных составляющих процесса порождения речи сконцентрируем внимание на той составляющей, которую А.А. Леонтьев называет внутренним программированием [10, с.8].

Характер внутреннего программирования определяет два основных фактора. Это, во-первых, задача высказывания, результирующая из мотива и цели, из определенных ситуативно-коммуникативных обстоятельств, из волевого и эмоционального состояния говорящего. Во-вторых, внутреннее программирование существенным образом определяется объективным содержанием отображаемой в высказывании ситуации (разумеется, в ее субъективном преломлении).

Внутреннее программирование характеризуется А.А. Леонтьевым как звено в составе речевого действия, которое, «управляя его конкретным осуществлением, в то же время не зависит от этого существования». Поскольку конкретно-языковые средства относятся к условиям осуществления внутренней программы речевого действия и в то же время непосредственно учувствует в самом процессе ее осуществления, эта программа предстает как посредник между отраженным объективным содержанием и его репрезентацией в речи. В этой своей функции внутренняя программа не может не определяться как некое отражение объективной ситуации, обращенное, однако, не только к ней, но и одновременно к потенциально пригодным для ее речевой репрезентации идиоэтническим языковым средствам. Это значит, что внутренняя программа сама и есть средство и способ перехода от одного к другому. Если существует какая-либо перспектива встроить понятие глубинной семантической структуры в теоретическое представление о речемыслительной реальности в качестве ее действительного и действенного звена, то, по нашему мнению, единственная возможность состоит в том, что «глубинная структура» по объекту совпадает с тем, что А.А. Леонтьев называет внутренней программой речевого действия. Он пишет: «Программа складывается из своего рода смысловых «вех», т.е. включает в себя коррелаты отдельных, особенно важных для высказывания его компонентов - таких, как субъект, предикат или объект...При переходе к внешней речи осуществляется развертывание каждого из этих компонентов в синтаксическую группу или отдельное слово плюс формы связи этих групп в предложении... Отсюда прямой путь к отношениям партиципантов и актантов, к «семантическим падежам» и т.п., т.е. ко всему тому, что прочно входит в аппарат теорий, которые основываются на постулате «синтаксиса и семантики», если даже соответствующая этому подходу «синтаксическая семантика» и не именуется «глубинной» [10,с.14]. Отсюда следует, что сказанное имеет отношение к затронутому выше вопросу о жизнеспособности «глубинных синтаксических структур», теоретически переосмысленных и переименуемых в «синтаксическую семантику», существенно независимую от формально-синтаксических способов ее конкретноязыковых репрезентаций, а потому и существенно универсально-языковую. Попутно укажем на связь всего в их отношениях к языковым понятиям или языковым категориям, в частности к грамматическим категориям.

Следуя за А.А. Леонтьевым в изображении структуры порождения высказывания, фокусируя при этом внимание на его «внутренней программе» - с некоторыми дополнительными акцентами в ее понимании. отметить, что конвергенции представляют «внутреннюю программу» и «глубинную семантическую структуру» синтаксических построений. В конвергенции этих понятий находит выражение фактическая общность современной лингвистической и психолингвистической проблематики: лингвист имеет дело с составом и структурой процесса речепорождения - безразлично, отдает ли он себе полностью отчет в этом или нет $[10$, с. 15] .

Мы убеждены в необходимости осмыслить понятие «глубинная семантическая структура» в единстве с идеей перехода от исходного этапа порождения речи к его конечному этапу. Исходный этап порождения речи - первичное, опосредованное универсально-общечеловеческими способами взаимодействия человека с окружающим миром отражение этого взаимодействия в конкретной ситуации [10, с.17]. Это перцептивный уровень 
отражения, на котором формируется сенсорная модель ситуации. В ней уже присутствуют элементы абстракции и обобщения, присутствуют расчлененность, отношения между компонентами ситуации, доминация одних компонентов над другими, их избирательная оценка в плане текущих мотивов и потребностей, связи с поведенческими реакциями, навыковые или ситуативно устанавливаемые с учетом меняющихся обстоятельств.

На конечном этапе идиоэтническими средствами конкретного языка как объективное содержание первичного перцептивного отражения презентируется как «мысль» об объекте деятельности, направленного внимания, представления, размышления и рассуждения.

Затронем некоторые установки методологического порядка. Во-первых, существует известное требование; в ходе научного поиска систематически исследовать природу понятий, посредством которых осуществляется познавательные операции.

Одна из важных задач этой деятельности состоит в анализе понятий предметных, субстантивно оформленных, с целью определить в этих понятиях характер и содержание того, что можно назвать их онтологическим аспектом. Вспомним фундаментальную схему Г. Фреге: термин указывает на объект и презентирует сознанию некоторые его признаки [15, с.28].

Термины, которые мы используем в рассуждениях, строя теоретическую модель объекта, подлежат в первую очередь испытанию на самостоятельную «внешность» их референтов. Далеко не всякое субстантивное выражение соотносительно - если вспомнить популярный пример Г. Фреге - с его «утренней звездой» или «вечерней звездой». Очень часто предметный по своей форме термин обозначает идеальный объект, не имеющий самостоятельного «вещного» соответствия в реальном мире, но способы обращения с этим термином в синтагматике рассуждений, в которые он включается, таковы, что он оказывается мысленно спроецированным на отдельную «вещную» реалию. Это гипостазирование [15.c.32].

Оно может быть более грубым и менее грубым, но оно всегда чревато затруднениями, которые преодолимы только вместе с искажениями онтологических образов, непосредственно вытекающими из гипостазирования как такового.

Один из менее грубых, так сказать, «неклассических» модусов гипостазирования состоит в том, что нечто, предметно, «вещно» существующее как компонент определенного целого и имеющее функциональную ценность только как компонент этого целого, в мысли односторонне обособляется от этого целого. Собствен- ная природа такого элемента системы представляет, конечно, известный интерес, так как существенна в общем плане взаимозависимость его субстрата и его функции (относительно системы, в которую он входит). Но в связи с задачами исследования зачастую оказывается более существенным или единственно существенным выяснение его функциональных свойств - в отвлечении от свойств субстратно - «вещных». Это особенно важно иметь в виду, когда сама «вещь» в целом должна рассматриваться в процессном аспекте ее существования, т.е. когда мы «договариваемся» даже до утверждения о ней, что это - не предмет, а процесс.

Эти методологические рассуждения мы связываем здесь с вопросом об онтологическом статусе «глубинной структуры». Ее характеристика - это характеристики этапа речемыслительного процесса, на котором исходный перцептивный материал преобразуется в систему элементов таким образом, что эта система в целом и поэлементно находит те или иные соответствия с языковыми средствами ее выражения, становится «соотносительный» с ними. Поскольку этап глубинного семантического структурирования ориентирован не преобразование исходного материала отражения в этом направлении, то на глубинное семантическое структурирование уже оказывают определенное влияние свойства конкретно-языковых образований и его независимость от последних лишь относительна.

Во-вторых, обратим внимание на положение о «раздвоении единого», о внутреннем противоречии, о единстве противоположностей как свойствах любого природного и социального явления. Дело, конечно, не в том, чтобы проповедовать эти истины, а в том, чтобы в нужный момент посмотреть на объект творческого осмысления с соответствующих позиций. В нашем случае это относится, прежде всего к тому системно-процессуальному целому, в котором соединяются «глубинные структуры» и идиоэтнический способ их речевого воплощения и презентации сознанию.

Исходя из вышесказанного следует заметить, что код «внутреннего программирования» должен соответствовать признаку непосредственного отображения существенных элементов объективной ситуации и признаку независимости от конкретно-языковых средств выражения содержания образа и в не меньшей мере - от выбора или другого способа выражения из парадигм конкретно-языковых синонимических средств, более или менее различающихся в семантическом плане.

Средством теоретического отображения такого кода явилось понятие «предметно-изобразительный код», разработанное Н.И. Жинкиным, который наряду с этим термином употребляется термин «универсально-предметный код», содержащий эксплицитное указание на то, 
что при его посредстве осуществляется общечеловеческие закономерности отражения объектов действительности в сознании людей [6, с.126].

Добавим, что в 70-80-е годы идеи Н.И.Жинкина получили фундаментальную поддержку со стороны физиологии мозга в исследованиях, прежде всего Л.я. Балонова В. Л., Деглина, посвященных функциональной асимметрии мозга, в которых обобщен богатый экспериментальный материал, свидетельствующий и о специализации функций полушарий, и об их интегративной взаимозависимости [1, с.87]. «Предметно-изобразительное» кодирование не только подтверждено и обогащено широким спектром фактов, но и обрело уточненную субстратнолокализационную характеристику.

Единство чувственного и рационального - неотъемлемое свойство пронизывает всю динамику опосредованных в текущих взаимодействиях элементов триады «мышление - сознание - знание». Это единство существует и функционирует благодаря языку.

В процессах его функционирования совершаются преобразования материала перцептивных познавательных образов в конкретно-языковые речемыслительные текстовые «продукты», одновременно категорирующие и элементы познавательного обреза, и образ в целом, и удерживающие в себе благодаря референционным связям отражения свойств единичного. Необходимо всячески настаивать на том, что, говоря о «глубинных структурах» и «поверхностных структурах», мы имеем в виду исходную и конечную фазы единого процесса. Его расчленение на эти фазы взаимосвязано с наблюдаемой в научной литературе довольно стойкой тенденцией к тому, чтобы, с одной стороны, на первую из них проецировать синтактико-семантическое структурирование, в действительности производимое в ходе всего процесса как целого, но реализуемое полностью только в его итоге, на его конечной фазе; с другой - конечная фаза предстает в таком изображении, как этап, на котором якобы уже сложившаяся синтактико-семантическая структура лишь получает формальное языковое выражение.

Соглашаясь с онтологическим отождествлением «Внутренней программы» и «предметно-изобразительного кода», укажем вместе с тем на одно, как нам кажется, существенное затруднение в трактовке этого явления. Как быть с признаком независимости перцептивного яруса отражения от конкретного языка, средствами которого реализуются в речи «внутренние программы», если экспериментально доказана «ословленность» перцептивных образов? Прямого ответа на этот вопрос мы в литературе не находим.

Предлагается следующий ответ на сформулированный выше вопрос, являющийся основным вопросом, которому подчинены наши рассуждения. Перцептивное отображение ситуации в предметно-изобразительном, наглядно-схемном коде, универсальном в его независимости от конкретно-языковой речи, есть момент, сторона, грань и одновременно этап процесса, в ходе которых чувственное отражение действительности, порождаемое практическим взаимодействием с нею (или непосредственно лишь внутренним, психическим воспроизведением такого взаимодействия) преобразуется В акт сознания. Всякая трансформация предполагает материал, который трансформируется, и средства, при помощи которых производится преобразование. Взаимодействие двух «сущностей» предполагает этап, когда они уже существуют, но еще независимы друг от друга. Подчеркнем, что для адекватности этого рассуждения требуется предпосылка «вещной», онтологической самостоятельности объектов, о которых идет речь; она требуется, в частности, для того, чтобы можно было говорить именно о взаимодействии объектов. В этой связи следует упомянуть о том, что существует неоспоримые факты, как правило, целесообразных, поведенческих реакций на чувственные образы как таковые, не «поднимающиеся» на уровень осознанности. Это свидетельствует об объективной «отдельности» перцептивного компонента отражательного механизма человека, поскольку в таких реакциях проявляется возможность его независимого функционирования. Вместе с тем это его свойство совмещается с наличием потенциальных и регулярно актуализируемых, притом в значительной мере стереотипированных, связей-корреляций элементов сенсорной модели мира с элементами той или иной языковой системы. Последние, вовлекаясь в речевое действие, преобразуют сенсорную модель ситуации в отражение, осознаваемое и осознанное через предмет в знаках, осмысленное, поддающееся анализу и проверке на адекватность, рефлексивное. Такое отражение осуществляется только посредством речи [2, с.134].

Раздвоенность единого, наличие в нем противоположных в каком-либо отношении сторон означает необходимость отражения «живого» противоречия и перехода противоположностей друг друга в концептуальной схеме исследуемого предмета-процесса. Его перцептивный момент и выделим из целостного процесса на объективном основании как звено и этап в развертывании этого процесса, и одновременно неотделим от него без утраты процессом его специфического интегрального качества.

Далее следует отметить аспект качественной однородности этого единого процесса как процесса отражательного и в этом смысле «семантического». В нем непосредственное перцептивное отражение нужно представлять себе в исходной точке не как уже ставшее, а как становящееся, совершающееся и, следовательно, в какой-то изначальный момент не как «ословленное», 
а как «ословливаемое» в самом ходе структурирования образа (еще на уровне несозноваемого сенсорного моделирования на базе обобщенных перцептивных образов-эталонов-продукта предшествующего когнитивного опыта) [1, с.154].

Обрисованный этап смыкается с этапом сличения формирующейся перцептивной структуры и хранимым в памяти семантическими эталонами, которые задаются системой языковых средств, так или иначе, коррелирующих с содержанием перцептивного отражении ситуации.

Из сказанного вытекает, что «глубинная семантическая структура» может быть отмечена лишь как скоротечно протекающий компонент в системе компонентов речемыслительного акта, как элемент процесса преобразования «перцептивной» семантики в семантику языковую.

Акцентрируя качество этого процесса как единого целого, следует тем самым одновременно наделить термин «глубинная семантическая структура» по преимуществу функцией выражения абстракции известной стороны, некоторого свойства этого целого. Вместе с тем то, на что этот термин указывает, вполне объективно - и в плане относительной самостоятельности самого существования соответствующего объекта, и в плане отображаемых «глубинно-семантическим» кодом содержаний.

Объективность «глубинных семантических структур» в этом последнем плане подтверждается тем, что из сферы явлений универсально-языковых они переходят в сферу конкретно-языковую: имеет место обращение «чисто» понятийных категорий без существенного изменения их содержания - именно в силу объективности их содержания - в языковые понятийные категории. Содержания «глубинных семантических структур» с полным на то основанием выявляется лингвистическими исследованиями как инварианты синонимических преобразований.

Конкретные языки могут различаться составами таких инвариантов, которые зависят от особенностей той или иной языковой системы. Однако следует полагать, что там, где существуют развитые системы синонимических средств (в первую очередь в современных национальных литературных языках), соответствующие объективно-содержательные варианты и высвобождаются в наибольшей мере из-под влияния конкретно-языковой «субъективности», и сближаются в разных языках друг с другом. Все же конкретно-языковая «субъективность» не может не сказываться как на номенклатуре подобных семантических образований, так и на их содержательной стороне. Следует помнить, однако, что важным механизмом преодоления конкретно-языковых различий в этом предельно абстрактном и одновременно предельно объективном аспекте семантического моделирования мира является комбинаторика элементов языковой системы в речи, что еще нередко упускается из виду в рассуждениях о так называемой лингвистической относительности. Смысловые инварианты синонимических преобразований - не просто модельно-теоретические идеальные объекты. Это в свою очередь вполне объективные реальности языкового сознания говорящих на определенном языке. Это продукты отвлечения и обобщения тех семантических оснований, которые составляют предпосылки действительных актов синонимических преобразований в обыденной речи.

Мы уже указали на один из тупиковых, по нашему мнению, ходов мысли, формирующей общее представление о речемыслительном процессе. Чисто предметный, доминантно «вещный» образ кодового воплощения продуктов перцепции неспособен преодолеть противоречие между одновременно универсально-общечеловеческим и идиоэтническим - под влиянием конкретного языка - характером восприятий. Укажем также на хорошо известную конфронтацию в сфере общей теории грамматики, где не прекращается дискуссия между сторонниками принципиальной формулы «синтаксис и семантика» и сторонниками идеи всеобщей дифференциальной значимости любых различающихся синтаксических и вообще языковых форм.

Нам кажется, что развиваемый здесь взгляд на «глубинные симантические структуры» как на (относительно) независимый тип содержательных образований дает основание в ходе лингвистического анализа и описания ставить акценты как на их собственном автономном содержании, так и на органическом взаимопроникновении этого содержания и семантики конкретно-языковых средств репрезентации этого содержания [11, с.13].

Расстановка акцентов может зависеть от частых исследовательских задач по «вычерпыванию» из объектов рассмотрения тех или иных групп признаков. Первостепенное значение имеет, однако, общая сознательная направленность разноаспектных исследований на взаимодополнении с целью - в идеале - всестороннего охвата свойств лингвистического объекта.

Обсуждая проблему взаимоотношений так называемых глубинных и поверхностных структур, мы не затрагивали по ходу изложения вопроса о возможных вариантах репрезентации глубинных структур поверхностными структурами в аспекте полноты содержания глубинной структуры в том или ином случае. Здесь мы можем сделать лишь некоторые намеки на перспективу осмысления этой стороны дела, в которой обнаруживается связи, переклички между отношениями элементов речемыслительного процесса в рамках отдельного вы- 
сказывания и аналогичными отношениями в широких масштабах дискурса и текста или речевого воплощения развернутых образов типа художественных.

Непосредственно языковая информация, заключения в отдельном высказывании, по параметру полноты может находиться в разных отношениях к содержанию перцептивного отражения ситуации действительности.

Языковое семантическое содержание высказывания может вычленяться как компонент совокупного се- мантического содержания высказывания, в частности, с учетом более факультативных, и более жестко детерминированных импликаций, обусловленных непосредственно языковой информацией.

В этом мы видим тот мостик общности, который ведет от проблематики целостных «глубинно-поверхностных» семантических содержаний отдельных минимальных высказываний к проблематике семантики «большого» связного текста.

\section{ЛИТЕРАТУРА}

1. Балонов Л.Я., Деглин В.Л. Слух и речь доминантного и недоминантного полушарий - Ленинград: Наука. Ленингр. отд-ние, 1976. - $218 c$.

2. Выготский Л.С. Мышление и Речь /. 5-ое изд., испр. М.: Лабиринт, 1999. 352 с.

3. Гумбольдт В. Лаций и Эллада // В. Гумбольдт. Избранные труды по языкознанию. — Избранные труды по языкознанию: Пер. с нем. / А.В. Гулыги и В.А. Звегинцева. - М.: ОАО ИГ «Прогресс», 2000. - $400 \mathrm{c}$.

4. Гумбольдт В. 0 мышлении и речи // В. Гумбольдт. Избранные труды по языкознанию. - М.: Прогресс, 1984. - 400 с.

5. Комлев Н.Г. Картина языка в словаре и грамматика Якоба Гримма // В. Гумбольдт и братья Гримм — труды и преемственность идей. 一 М.: Изд-во МГУ, 1987. С. 24-46.

6. Жинкин Н.И. Язык, Речь Творчество. М.: Лабиринт, 1998. -364с.

7. Кацнельсон С.Д. Общее и типологическое языкознание. Изд. 2, доп. 2010. 344 с.

8. Кацнельсон С.Д. Содержание слова, значение и обозначение. Изд. 3. 2011. 112 с.

9. Кацнельсон, С.Д. Типология языка и речевое мышление / С.Д. Кацнельсон. - М.: Эдиториал УРСС, 2009. 218с.

10. Леонтьев А.А. «Психологические единицы и порождение речевого высказывания» М., КомКнига, 2005 - $306 c$.

11. Литвинов В.П. Понятие дискурса у Мишеля Фуко // Вопросы германской филологии. Вып.1: Юбилейный сборник научных трудов кафедры немецкой филологии - Пятигорск: Изд-во ПГЛУ, $1999-$ с.7-20.

12. Литвинов В.П. Мышление Ноама Хомского: Курс лекций / Международная академия бизнеса и банковского дела. — Тольятти, 1999 -118с.

13. David Sorkin, Wilhelm Von Humboldt: The Theory and Practice of Self-Formation (Bildung), 1791—1810 in: Journal of the History of Ideas, Vol. 44 , No. 1 (Jan. — Mar., 1983), pp. 55-73

14. Elsina Stubb, Wilhelm Von Humboldt's Philosophy of Language, Its Sources and Influence, Edwin Mellen Press, 2002. - 332p.

15. Frege G. Über Sinn und Bedeutung //Frege G. Funktion, Begriff, Bedeutung. Fünf logieche Studien. Göttingen, 1966. - S.47.

16. John Roberts, German Liberalism and Wilhelm von Humboldt: A Reassessment, Mosaic Press, 2015.-142p.

(c) Абдукадырова Тумиша Таштиевна (tumischa-uni@mail.ru), Арсаханова Малютхан Абдул-Хаджиевна (arsahanova@mail.ru). 